\title{
Endothelial nitric oxide synthase gene polymorphism is associated with sickle cell disease patients in India
}

\author{
Sudhansu Sekhar Nishank ${ }^{1}$, Mendi Prema Shyam Sunder Singh ${ }^{1}$, Rajiv Yadav ${ }^{1}$, Rasik Bihari Gupta ${ }^{2}$, \\ Vijay Sadashiv Gadge ${ }^{1}$ and Anil Gwal ${ }^{1}$
}

\begin{abstract}
Patients with sickle cell disease (SCD) produce significantly low levels of plasma nitric oxide (NO) during acute vaso-occlusive crisis. In transgenic sickle cell mice, NO synthesized by endothelial nitric oxide synthase (eNOS) enzyme of vascular endothelial cells has been found to protect the mice from vaso-occlusive events. Therefore, the present study aims to explore possible association of eNOS gene polymorphism as a potential genetic modifier in SCD patients. A case control study involving 150 SCD patients and age- and ethnicity-matched 150 healthy controls were genotyped by PCR-restriction fragment length polymorphism techniques for three important eNOS gene polymorphisms-eNOS $4 \mathrm{a} / \mathrm{b}$, eNOS 894G $>$ T and eNOS $-786 \mathrm{~T}>\mathrm{C}$. It was observed that SCD patients had significantly higher frequencies of mutant alleles besides heterozygous and homozygous mutant genotypes of these three eNOS gene polymorphisms and low levels of plasma nitrite $\left(\mathrm{NO}_{2}\right)$ as compared with control groups. The SCD severe group had significantly lower levels of plasma $\mathrm{NO}_{2}$ and higher frequencies of mutant alleles of these three SNPs of eNOS gene in contrast to the SCD mild group of patients. Haplotype analysis revealed that frequencies of one mutant haplotype '4a-T-C' (alleles in order of eNOS 4a/b, eNOS 894G $>$ T and eNOS $-786 \mathrm{~T}>\mathrm{C}$ ) were significantly high in the severe SCD patients $(P<0.0001)$, whereas the frequency of a wild haplotype '4b-G-T' was found to be significantly high $(P<0.0001)$ in the SCD mild patients, which indicates that eNOS gene polymorphisms are associated with SCD patients in India and may act as a genetic modifier of the phenotypic variation of SCD patients.
\end{abstract}

Journal of Human Genetics (2013) 58, 775-779; doi:10.1038/jhg.2013.99; published online 3 October 2013

Keywords: eNOS gene; genotypes; haplotype; nitric oxide; sickle cell disease

\section{INTRODUCTION}

Sickle cell anemia in humans is an autosomal recessive disorder and the most common genetic disease affecting individuals from tropical and subtropical Africa, the Arabian Peninsula, India, Central America and the United States of America. ${ }^{1}$ It is caused by homozygosity for a single amino-acid change $\mathrm{Glu} \rightarrow \mathrm{Val}$ at $\beta^{6}$ position of chromosome 11 for the $\beta$ subunit of hemoglobin. Among the children with sickle cell anemia, vaso-occlusive crisis is the most common cause of hospitalization followed by acute chest syndrome (ACS) leading to significant risk of morbidity and mortality. The underlying pathophysiology of SCA is largely due to microvascular occlusion by sickled erythrocytes, resulting in localized tissue ischemia and pain. Recent studies indicate that upto $50 \%$ of patients with sickle cell disease (SCD) have endothelial dysfunction due to impaired bioavailability of endogenous nitric oxide (NO) caused by scavenging of NO by cell-free plasma hemoglobin and consumption of L-arginine amino acid by cell-free arginase enzyme released from hemolysed red blood cell. ${ }^{2}$ Reduced endothelial NO bioavailability in SCD leads to activation of endothelial cell adhesion molecules such as VCAM-1, ICAM-1, P-selectin and E-selectin besides platelet activation, which in turn culminate into vascular occlusion and vaso constriction. The impaired NO bioavailability due to significant intravascular hemolysis produces many complications such as pulmonary hypertension, priapism, leg ulcer, stroke, renal insufficiency, esophageal dysmotility and abdominal pain in SCD patients. ${ }^{3}$ In vivo, NO is synthesized during the enzymatic conversion of L-arginine to L-citrulline by three isoforms of nitric oxide synthase (NOS) enzyme, namely, inducible NOS, endothelial NOS (eNOS) and neuronal NOS (nNOS). Endogenous NO synthesized by the eNOS enzyme, has been shown to have an important role in the pathogenesis of both VOC and ACS in sickle cell transgenic mice and sickle cell transgenic murine models. These studies assign eNOS gene to be a critical regulator of vasodilation and inhibitor of cell adhesion and aggregation, protecting the animal from vaso occlusion. ${ }^{4}$ In normal healthy individuals, the level of plasma NO in the body is found to be linked to allelic variation of the eNOS gene. ${ }^{5}$ The most important allelic variants of the eNOS gene responsible for bringing about variation in NO levels are-eNOS -786T $>$ C ( rs2070744) in promoter region, eNOS $894 \mathrm{G}>\mathrm{T}$ in exon 7 (Glu298Asp, rs1799983) and eNOS $4 \mathrm{a} / \mathrm{b}$, a $27-\mathrm{bp}$ variable number of tandem repeats in intron

${ }^{1}$ Regional Medical Research Centre for Tribals (ICMR), Nagpur Road, PO-Garha, Jabalpur, Madhya Pradesh, India and ${ }^{2}$ Indian Council of Medical Research, Head Quarter, Ansari Nagar, New Delhi, India

Correspondence: Dr SS Nishank, Division of Genetics, Regional Medical Research Centre for Tribals (ICMR), Nagpur road, PO- Garha, Jabalpur-482003, Madhya Pradesh, India. E-mail: nishank25@gmail.com

Received 28 April 2013; revised 10 August 2013; accepted 28 August 2013; published online 3 October 2013 
4 (chromosome $7 \mathrm{q} 35-\mathrm{q} 36$ ). These eNOS variants have been found to be associated with several vascular disorders such as myocardial infarction, ${ }^{6}$ atherothrombosis, ${ }^{7}$ erectile dysfunction, ${ }^{8}$ stroke ${ }^{9}$ and renal disease ${ }^{10}$ in normal general population of Asian and European origin. As compared with these reports, eNOS gene polymorphism has been less studied in the SCD population where these symptoms are also observed. Only one eNOS gene polymorphism, eNOS $-786 \mathrm{~T}>\mathrm{C}$ variant, has been linked to ACS in Mediterranean SCD children as well as African-American female SCD patients with or without any gender differences. ${ }^{11,12}$ However, there is no report on the role of eNOS polymorphism in pathogenesis of sickle cell patients in India, where about $1-34 \%$ population from different ethnic communities have the sickle cell gene. ${ }^{13}$ Amongst the normal population of India, eNOS gene variants have been linked to ACS and early pregnancy loss. ${ }^{14}$ Further, the eNOS gene locus has been reported to be responsible for variable concentration of $\mathrm{NO}$ in the normal individuals in India. ${ }^{15}$ Therefore, the present study was initiated to explore possible association of eNOS gene polymorphism as a potential genetic modifier with SCD patients in India.

\section{MATERIALS AND METHODS}

\section{Study subjects}

The SCD patients attending sickle cell clinic (of Regional Medical Research Centre for Tribals (ICMR) situated in the campus of NSB Medical College, Jabalpur, Madhya Pradesh) for regular follow-up were the study participants. Similarly, age-matched and ethnicity-matched normal healthy individuals (those having normal hemoglobin phenotype, $\mathrm{Hb} \mathrm{AA}$ ) enrolled for routine diagnosis of haemoglobinopathies in the Department of Genetics were used as controls for comparison of eNOS gene polymorphism between these two groups. Both controls and disease patients belonged to scheduled caste, scheduled tribes, OBC, general caste communities of the state of Madhya Pradesh only. A total of 150 SCD patients and age- and ethnicity-matched 150 normal/control individuals were collected from different families for this study during the period from March 2012 to November 2012. Patients receiving recent or multiple blood transfusion and infection and pregnant women were excluded from the study. The SCD patients were further classified into mild and severe phenotypes based on severity index (SI) as per the formula propounded by El-Hazmi. ${ }^{16}$ An SI was calculated based on frequency of painful crises, hospitalization, blood transfusion, infection and specific complications during the previous years starting from the birth of the child. The SI score was $\leqslant 6.0$ for mild and $\geqslant 6.1$ for the severe SCD patients. Amongst 150 SCD patients, 32 patients were mild, 118 patients were severe according to the SI. Of the 150 patients, 5 patients were HbS- $\beta$ thalassemia and the rest belonged to sickle cell anemia (Hb SS). Blood sample for DNA analysis and plasma were collected after written consent from the patient and his/her legal parents was obtained. An ethical committee constituted jointly by RMRCT (ICMR), Government of India and NSB Medical College, Government of Madhya Pradesh approved this study (file No.237/ethical/ RMRCT/4th Feb 2012). The present study was conducted in accordance with the ethical standards of Helsinki Declaration.

\section{DNA isolation and genotyping}

Genomic DNA was extracted by blood genomic DNA extraction kit (Fermentas, Schwerte, Germany) as per manufacturer's instruction. The $\mathrm{T} \rightarrow$ $\mathrm{C}$ transition at position -786 in the $5^{\prime}$ flanking region of the $e N O S$ gene was investigated by performing PCR-restriction fragment length polymorphism analysis using forward primer $5^{\prime}$-GAGTCTGGCCAACACAAATCC-3' and reverse primer $5^{\prime}$-GACCTCTAGGGTCATGCAGGT- $3^{\prime}$. The PCR fragment (657 bp) was digested with $\mathrm{Hpa}$ II restriction enzyme overnight at $37^{\circ} \mathrm{C}$. The wild-type sequence $(-786 \mathrm{~T})$ was not cleaved, whereas the mutant sequence $(-786 \mathrm{C})$ was cleaved into two fragments (373 and $284 \mathrm{bp}$ ). ${ }^{17}$ Genotyping of the eNOS $894 \mathrm{G}>\mathrm{T}$ polymorphism was done by PCR amplifying exon 7 using sense primer $5^{\prime}$-AAGGCAGGAGACAGTGGATGGA $-3^{\prime}$ and antisense primer $5^{\prime}$ -
CCCAGTCAATCCCTTTTGGTGCTCA- $3^{\prime}$ followed by digestion of the PCR product (248bp) with $\mathrm{Mbo}$ I restriction enzyme overnight at $37^{\circ} \mathrm{C} .{ }^{18}$ The mutant allele $894 \mathrm{~T}$ was cleaved into two fragments (158 and $90 \mathrm{bp}$ ). The 27-bp repeat VNTR in intron 4 (eNOS 4a4b) was differentiated only by allele-specific PCR. The sequences of flanking primers used were 5'-AGGCCCTA TGGTAGTGCCTTT- $3^{\prime}$ (sense) and $5^{\prime}$-TCTCTTAGTGCTGTGGTCAC- $3^{\prime}$ (antisense). Mutant allele eNOS 4a (4 repeats) produced a 393-bp fragment and the wild-type allele eNOS $4 \mathrm{~b}$ (5 repeats) produced a 420 -bp fragment. ${ }^{8}$ To ensure that there was no error in genotyping, about $10 \%$ of the randomly selected samples were regenotyped for intron 4VNTR and $-786 \mathrm{~T}>\mathrm{C}$, whereas genotyping for the $894 \mathrm{G}>\mathrm{T}$ was repeated for all of the samples and the results were found to be $100 \%$ concordant.

\section{Plasma nitrite assay}

Plasma samples from patients with acute renal failure and patients on medications, such as long-acting nitrates (sorbitate), were excluded from the study. Plasma from patients who had consumed low-nitrite $\left(\mathrm{NO}_{2}\right)$ food $12 \mathrm{~h}$ before collection were included, and to eliminate the possibility of nitrate contamination of EDTA tubes, the tubes were prewashed with Milli Q (Millipore, Billerica, MA, USA) water. In addition, the EDTA solution used had undetectable levels of $\mathrm{NO}_{2}$. Plasma $\mathrm{NO}_{2}$ was measured after enzymatic conversion of $\mathrm{NO}_{3}{ }^{-}$to $\mathrm{NO}_{2}^{-}$by nitrate reductase in duplicate according to the manufacturer's instructions using a commercial ELISA based kit (Enzo Life Sciences AG, Lausen, Switzerland).

\section{Statistical analysis}

All statistical analysis were performed with statistical software Graph Pad Prism (La Jolla, CA, USA, version 5.0). The association of genotypes and allele frequencies between the two clinical groups was determined by computing the odds ratio derived from a two-tailed Fisher's exact test. The $X^{2}$-test was also used to test the Hardy-Weinberg equilibrium. Statistical significance was defined as a $P$-value of $<0.05$. Linkage disequilibrium was examined by $X^{2}$ analysis, and the extent of disequilibrium was determined as follows: $\mathrm{D}^{\prime}=\mathrm{D} /$ $\mathrm{D}_{\max }$. The SNP Alyze program (version 8.0, Dynacom Dynamic Communication, Chiba, Japan) based on the expectation maximization algorithm was used to estimate the maximum likelihood of haplotype frequencies in each group and to identify which specific haplotypes were associated with a clinical outcome of SCD patients. A $P$-value of $<0.00625$ ( $0.05 /$ number of haplotypes) was considered significant to correct for the number of comparisons made. The median plasma $\mathrm{NO}_{2}$ levels were compared by using the Mann-Whitney $U$-test.

\section{RESULTS}

The mean age of the study sample was found to be 16.3 ( \pm 6.5 , s.d.) years for SCD patients, 17.6 ( \pm 6.8 , s.d.) years for the control group. The distribution of genotypes for three polymorphic variants of the eNOS gene such as eNOS $4 \mathrm{a} / \mathrm{b}$, eNOS $894 \mathrm{G}>\mathrm{T}$ and eNOS $-786 \mathrm{~T}>\mathrm{C}$ is summarized in Table 1 . The incidence of heterozygous mutant genotypes (particularly $4 \mathrm{a} / 4 \mathrm{~b}$ of eNOS $4 \mathrm{a} / \mathrm{b}$ and $\mathrm{T} / \mathrm{C}$ of eNOS $-786 \mathrm{~T}>\mathrm{C})$, homozygous mutant genotypes $(4 \mathrm{a} / 4 \mathrm{a}, \mathrm{T} / \mathrm{T}, \mathrm{C} / \mathrm{C}$ of eNOS $4 \mathrm{a} / \mathrm{b}$, eNOS $894 \mathrm{G}>\mathrm{T}$ and eNOS $-786 \mathrm{~T}>\mathrm{C}$, respectively) and mutant alleles ('4a', 'T', 'C' of eNOS 4a/b, eNOS $894 \mathrm{G}>\mathrm{T}$ and eNOS $-786 \mathrm{~T}>\mathrm{C}$, respectively) of these three SNPs of the eNOS gene were found to be significantly high in the SCD group than in controls.

After classification of SCD patients into mild and severe categories based on their SI, it was observed that the SCD severe patients (Table 2) had significantly higher frequencies of mutant alleles (' $4 a$ ', ' $\mathrm{T}$ ' and ' $\mathrm{C}$ ') and mutant genotypes (both heterozygous mutants such as $4 \mathrm{a} / 4 \mathrm{~b}, \mathrm{G} / \mathrm{T}$ and $\mathrm{T} / \mathrm{C}$ as well as homozygous mutants such as $4 \mathrm{a} / 4 \mathrm{a}$, $\mathrm{T} / \mathrm{T}$ and $\mathrm{C} / \mathrm{C}$ ) of these three SNPs of eNOS genes compared with the SCD mild patients. On the other hand, there were higher incidences of wild alleles (' $4 \mathrm{~b}$ ', ' $\mathrm{G}$ ' and ' $\mathrm{T}$ ') as well as wild genotypes ( $4 \mathrm{~b} / 4 \mathrm{~b}, \mathrm{G} / \mathrm{G}$ and $\mathrm{T} / \mathrm{T}$ ) of eNOS gene polymorphisms among the SCD mild group of patients than the SCD severe group. Further, there were 
Table 1 Genotype frequencies for various eNOS polymorphisms in the SCD patients and the control group

\begin{tabular}{ccccc}
\hline Genotype & $\begin{array}{c}\text { SCD patient } \\
\mathrm{n}=150\end{array}$ & $\begin{array}{c}\text { Control group } \\
\mathrm{n}=150\end{array}$ & $\begin{array}{c}\text { Odds ratio } \\
\text { confidence interval) }\end{array}$ & P-value $^{\mathrm{a}}$ \\
\hline eNOS 4a/b & & & & \\
4b/4b & $24(16.0 \%)$ & $80(53.3 \%)$ & $0.1667(0.096-0.286)$ & $<0.0001$ \\
4a/4b & $85(56.6 \%)$ & $62(41.3 \%)$ & $1.856(1.174-2.935)$ & 0.0109 \\
4a/4a & $41(27.3 \%)$ & $8(5.3 \%)$ & $6.67(3.0-14.83)$ & $<0.0001$ \\
& & & & \\
$894 G>T$ & & & & \\
G/G & $41(27.3 \%)$ & $89(59.3 \%)$ & $0.257(0.158-0.418)$ & $<0.0001$ \\
G/T & $73(48.6 \%)$ & $59(39.3 \%)$ & & $\mathrm{NS}$ \\
$\mathrm{T} / \mathrm{T}$ & $36(24 \%)$ & $2(1.33 \%)$ & $23.37(5.509-99.13)$ & $<0.0001$
\end{tabular}

\begin{tabular}{crrrr}
$-786 T>C$ & & & & \\
$\mathrm{~T} / \mathrm{T}$ & $46(30.6 \%)$ & $90(60.0 \%)$ & $0.294(0.183-0.475)$ & $<0.0001$ \\
$\mathrm{~T} / \mathrm{C}$ & $79(52.6 \%)$ & $58(38.6 \%)$ & $1.765(1.115-2.793)$ & 0.0203 \\
$\mathrm{C} / \mathrm{C}$ & $25(16.6 \%)$ & $2(1.33 \%)$ & $14.8(3.436-63.74)$ & $<0.0001$ \\
\hline
\end{tabular}

Abbreviations: eNOS, endothelial nitric oxide synthase; $S C D$, sickle cell disease;

NS, not significant.

aBy Fisher's two-tailed exact test, sample frequency expressed as no. (\%).

Table 2 Genotype frequencies for various eNOS polymorphisms in the SCD mild and SCD severe patients

\begin{tabular}{|c|c|c|c|c|}
\hline Genotypes & $\begin{array}{l}S C D \text { mild } \\
\mathrm{n}=32\end{array}$ & $\begin{array}{c}\text { SCD severe } \\
\mathrm{n}=118\end{array}$ & $\begin{array}{c}\text { Odds ratioa (95\% } \\
\text { confidence interval) }\end{array}$ & P-value \\
\hline \multicolumn{5}{|l|}{ eNOS $4 a / b$} \\
\hline $4 b / 4 b$ & $15(46.9 \%)$ & $9(10.0 \%)$ & $0.1(0.03-0.24)$ & $<0.0001$ \\
\hline $4 a / 4 b+4 a /$ & $17(53.1 \%)$ & 109 (92.4\%) & $10.7(4.04-28.24)$ & $<0.0001$ \\
\hline \multicolumn{5}{|l|}{$4 a$} \\
\hline \multicolumn{5}{|l|}{$894 G>T$} \\
\hline $\mathrm{G} / \mathrm{G}$ & $21(65.6 \%)$ & $20(17.0 \%)$ & $0.1(0.04-0.25)$ & $<0.0001$ \\
\hline $\mathrm{G} / \mathrm{T}+\mathrm{T} / \mathrm{T}$ & $11(34.3 \%)$ & $98(83.0 \%)$ & $9.35(3.9-22.42)$ & $<0.0001$ \\
\hline \multicolumn{5}{|l|}{$-786 T>C$} \\
\hline $\mathrm{T} / \mathrm{T}$ & $25(78.1 \%)$ & $21(17.7 \%)$ & $0.06(0.02-0.15)$ & $<0.0001$ \\
\hline $\mathrm{T} / \mathrm{C}+\mathrm{C} / \mathrm{C}$ & $7(21.8 \%)$ & $97(77.1 \%)$ & $16.5(6.3-43.97)$ & $<0.0001$ \\
\hline
\end{tabular}

Abbreviations: eNOS, endothelial nitric oxide synthase; SCD, sickle cell disease.

aBy Fisher's two-tailed exact test, sample frequency expressed as no. (\%).

no gender-wise differences in allelic and genotypic distribution (data not shown).

When median plasma $\mathrm{NO}_{2}$ concentrations were considered according to eNOS genotypes (Supplementary Table 1), it was found that the SCD severe patients having mutant variants of the eNOS gene had significantly lower levels of plasma $\mathrm{NO}_{2}$ in contrast to the SCD mild patients and control group of individuals. However, median plasma $\mathrm{NO}_{2}$ levels did not show any significant differences between the eNOS genotypes in control group. The mean level of plasma $\mathrm{NO}_{2}$ was found to be $243.4 \mu \mathrm{M}( \pm 24.6$, s.d. $)$ in the SCD population $(n=150)$, which differed significantly $(P<0.0001)$ from the control group $263.9 \mu \mathrm{M}$ $\left( \pm 10.9\right.$, s.d. $(n=150)$. The mean level of $\mathrm{NO}_{2}$ was $237.3 \mu \mathrm{M}( \pm 23.3)$ in the SCD severe group and $265.9 \mu \mathrm{M}( \pm 14.4)$ in the SCD mild group (data of mean values of $\mathrm{NO}_{2}$ level shown in Supplementary Table 1). No significant differences in mean $\mathrm{NO}_{2}$ level between the control group and the SCD mild group was observed. Similarly, there was absence of gender-specific level of plasma NO (data not shown).
Table 3 Distribution of eNOS gene haplotypes frequencies among the control and SCD individuals

\begin{tabular}{|c|c|c|c|c|c|}
\hline & $\begin{array}{l}\text { eNOS } 4 a / b \\
\text { eNOS } 894 G>T\end{array}$ & & & & \\
\hline eNOS & eNOS & & & Odds ratiob $(95 \%$ & \\
\hline haplotypes ${ }^{\mathrm{a}}$ & $-786 T>C$ & Control & $S C D$ & confidence interval) & $P$-value ${ }^{\mathrm{b}}$ \\
\hline Hap 1 & 4b-G-T & 0.74 & 0.413 & $4.0(2.85-5.7)$ & $<0.0001$ \\
\hline Hap 2 & $4 a-T-C$ & 0.22 & 0.397 & $3.39(2.18-5.26)$ & $<0.0001$ \\
\hline Hap 3 & 4a-G-T & 0.0367 & 0.092 & $5.14(2.30-11.45)$ & $<0.0001$ \\
\hline Hap 4 & $4 a-T-T$ & 0.0033 & 0.056 & $29.51(3.73-233.68)$ & 0.0015 \\
\hline
\end{tabular}

Table 4 Distribution of eNOS gene haplotypes frequencies among the SCD mild and SCD severe individuals

\begin{tabular}{lcclcc}
\hline \multicolumn{7}{c}{ eNOS 4a/b eNOS } & & & & \\
eNOS & 894 G $>$ T eNOS & Mild & Severe & Odds ratio $(95 \%$ \\
haplotypes $^{\mathrm{a}}$ & $-786 T>C$ & $S C D$ & $S C D$ & confidence interval) & P-value $^{\mathrm{b}}$ \\
\hline Hap 1 & 4b-G-T & 0.656 & 0.347 & $3.55(2.53-4.97)$ & $<0.0001$ \\
Hap 2 & 4a-T-C & 0.125 & 0.473 & $11.11(4.24-29.11)$ & $<0.0001$ \\
Hap 3 & 4a-G-T & 0.109 & 0.088 & $1.61(0.51-5.10)$ & 0.42 \\
Hap 4 & 4a-T-T & 0.109 & 0.039 & $0.37(0.09-1.47)$ & 0.16 \\
\hline
\end{tabular}

Abbreviations: eNOS, endothelial nitric oxide synthase; SCD, sickle cell disease

aHaplotype analysis by SNP Alyzer 8.0 software.

bOdds ratio and $P$-value by two-tailed Fisher's exact $X^{2}$-test.

In the present study, predominantly fourtypes of eNOS gene polymorphisms haplotypes (H-haplotypes, alleles order being eNOS $4 \mathrm{a} / 4 \mathrm{~b}, 894 \mathrm{G}>\mathrm{T}$ and eNOS-786T $>\mathrm{C}$, respectively, in each haplotype) were observed. The SCD patients had significantly higher prevalence of haplotypes such as H2 (4a-T-C), H3 (4a-G-T) and $\mathrm{H} 4$ (4a-T-T), whereas controls had higher prevalence of haplotype $\mathrm{H} 1$ (4b-G-T) (Table 3).

Comparison of haplotype distribution between the mild and severe SCD patients (Table 4) revealed that the mild SCD patients had higher incidence of $\mathrm{H} 1$ haplotype, which comprises of wild alleles of all three SNPs of the eNOS gene, whereas the SCD severe patients had significantly higher frequencies of $\mathrm{H} 2$ haplotype, which comprises of mutant alleles of all three SNPs of the eNOS gene. All three SNPs were found to have significantly strong linkage disequilibrium with each other (Supplementary Table 2) among the SCD patients. Besides, distribution of alleles of eNOS gene polymorphism were in line with Hardy-Weinberg equilibrium distribution for the SCD population.

\section{DISCUSSION}

In the present study, the higher prevalence of mutant alleles and mutant genotypes of three SNPs of the eNOS gene observed in SCD individuals as compared with controls imply that eNOS gene polymorphism is associated with sickle cell disease in India. The finding of higher incidence of mutant alleles and genotypes among the SCD severe group in contrast to higher incidence of wild alleles and genotypes among the SCD mild group of patients indicates that the eNOS gene probably acts as a genetic modifier of phenotypic variation among SCD patients in India. 
Throughout the world there are few available reports on the association of these three SNPs of the eNOS gene with SCD disease. Study of SCD patients from Brazil revealed lack of association of these three SNPs of the eNOS gene with sickle cell disease. ${ }^{19}$ However, two separate studies conducted by Chaar et al. ${ }^{11}$ and Sharan et al. ${ }^{12}$ on SCD children and SCD female subjects, respectively, found significant association of only one SNP eNOS $-786 \mathrm{~T}>\mathrm{C}$ with SCD with respect to symptom of ACS, where females having this eNOS variant were found to be more susceptible to ACS. This discrepancy in results from ours may be caused by variety of factors such as sample sizes, ethnic heterogeneity and environmental factors.

The low level of plasma $\mathrm{NO}_{2}$ along with significant association of mutant variants of the eNOS gene observed among the SCD severe patients in contrast to the SCD mild patients in current study indicates that the eNOS gene and the eNOS-derived NO may be involved in differentiation of clinical manifestations between severe and mild group of sickle of SCD patients.

It has already been observed that the level of plasma NO gets reduced significantly during acute vaso-occlusive crises in SCD patients. $^{20}$ However, there is lack of functional studies on the relation of the eNOS gene polymorphism and plasma NOx levels in SCD patients. On the other hand, functional relation between the eNOS gene and plasma NOx levels have been studied in other nonSCD patients, mostly patients suffering from osteonecrosis, hypertension, carotid atherosclerosis and coronary disease. These studies have, however, produced contradictory results. For instance, among the patients with coronary artery disease, eNOS gene polymorphisms were found to be associated with either high plasma NOx levels ${ }^{21}$ or no effects on NOx level. ${ }^{22}$ However, several workers from different parts of the world have found low plasma NOx level associated with mutant variants of three SNPs of eNOS gene polymorphism (those SNPs that we have studied in the present work) among these patients. ${ }^{5,8,10,15,23-26}$ Our findings of low level of plasma NOx associated with mutant variants of the eNOS gene is thus supported by these latter group of studies. The absence of genderbiased differences in eNOS gene polymorphism as well as plasma NOx levels in our findings agrees with that of earlier Indian studies of patients susceptible to cardio vascular disease by Shankarishan et al. ${ }^{27}$ Similarly, in the present series, the lack of difference in plasma $\mathrm{NO}_{2}$ levels between different eNOS gene polymorphisms in control group supports to that of an earlier observation among the normal population of South India by Angeline et $a .^{28}$ as well as the findings of Nagasaki et al. ${ }^{29}$ observed among Japanese healthy individuals.

In the present study, the SCD patients were found to be significantly associated with mutant eNOS gene polymorphism than controls. Thus, as compared with controls, specific haplotypes comprising of mutant alleles of eNOS SNPs such as Haplotype-2 (4a-T-C), Haplotype-3(4a-G-T) and Haplotype-4 (4a-T-T) have been found significantly in a higher proportion among the SCD patients.

The observation of a specific mutant haplotype $\mathrm{H} 2$ (4a-T-C) in higher proportion among the SCD severe categories than among the SCD mild group in our study may be due to higher incidence of mutant alleles of three SNPs of the eNOS gene, which are in strong linkage disequilibrium with each other, causing lowering of its activity and low level of plasma NOx in our studied samples. This is supported by the observations of Wang et al. ${ }^{10}$ and Fatini et al. ${ }^{23}$ who reported that the eNOS $-786 \mathrm{C}$ variant at promoter region is mostly in linkage disequilibrium with ' $4 a$ ' allele at intron 4 as well as eNOS 894T variant of exon7 affecting the transcriptional efficiency of the eNOS gene in haplotype-dependent manner among hyperhomocysteinemia patients, making them more susceptible to acute coronary syndrome. This haplotype-dependent manner of functional efficiency of eNOS gene polymorphism may be the reason for increased incidence of haplotype ' $4 \mathrm{a}-\mathrm{T}-\mathrm{C}$ ' among the SCD severe patients in our study, and this haplotype may be responsible for lowering plasma NOx synthesis in these SCD severe patients than in the SCD mild patients.

There are several evidences in support of relation of mutant eNOS gene haplotypes with low level of plasma NO in general population of different parts of the world. One evidence in India by earlier workers found that diabetic nephropathy patients of north India had low NO level when patients carried the '4a-T-C' haplotype. ${ }^{14}$ Similarly, haplotypes of eNOS gene polymorphism comprising of different combinations of mutant alleles, particularly, 4a-T-T, 4b-G-C and $4 \mathrm{~b}-\mathrm{T}-\mathrm{C}$ have also been found to be significantly associated with low plasma $\mathrm{NO}_{2}$ concentration. ${ }^{30-33}$ Although some of these later haplotypes have been observed in our study, they assume no significance due to their low frequency and small sample size.These evidences indicate that in our study, Haplotype-2 (H2) might be associated with low level of NO synthesis in the severe SCD patients. On the other hand, the presence of $\mathrm{H} 1$ haplotype (4b-G-T) that comprises of wild alleles of all three SNPs of the eNOS gene along with higher level of plasma $\mathrm{NO}_{2}$ level among both the SCD mild and the control group imply that this $\mathrm{H} 1$ haplotype may be protective against clinical severity among the SCD mild individuals.

The strong linkage disequilibrium between three SNPs of the eNOS gene point to the fact that these SNPs combinedly influence clinical phenotypes of SCD patients in our study. Further, the distribution of three SNPs of the eNOS gene in the present study among SCD population is without any selection pressure as evidenced from lack of deviation of these SNPs from Hardy-Weinberg equilibrium distribution. $\alpha$-thalassemia and $\beta^{s}$ haplotype are found to be important genetic modifiers of SCD patients. Raised HbF (fetal hemoglobin) due to specific $\beta^{s}$ haplotype and association of $\alpha$-thalassemia produces milder clinical course in SCD patients. ${ }^{34}$ In the present study, higher incidence of $\alpha$-thalassemia $(-\alpha / \alpha \alpha$ and $-\alpha /-\alpha$ genotypes) in the SCD mild group and higher incidence of normal $\alpha$-globin genotype $(\alpha \alpha)$ $\alpha \alpha$ ) in the SCD severe group were observed (data not shown), which add to the fact that eNOS gene polymorphism may also be an additional genetic modifier of clinical course of SCD patients besides other genetic modifiers such as $\alpha$-thalassemia and $\beta^{\text {s }}$ haplotypes.

The prevalence of sickle cell genotypes (heterozygotes and homozygotes) in India varies from $0-34 \%$ in different population groups. The state of Madhya Pradesh situated in sickle cell belt of India, has the most sickle homozygotes (34\%) followed by the state of Gujrat, Maharashtra, Andhra Pradesh and Orissa. ${ }^{13}$ In our study, the association of eNOS gene polymorphism with SCD patients along with low level of plasma $\mathrm{NO}_{2}$ among the severe SCD patients in contrast to the mild SCD patients indicates that the eNOS gene may act as another genetic modulator of clinical variation of sickle cell disease, which may be mediated through synthesis of low level of NO by the mutant eNOS gene. The present finding of the eNOS gene association with SCD patients of Madhya Pradesh (a state of Central India) may be helpful to initiate early antenatal prediction of clinical severity and development/administration of NO-based therapies. The higher incidence of specific mutant haplotype ' $4 \mathrm{a}-\mathrm{T}-\mathrm{C}$ ' associated with low level of median plasma $\mathrm{NO}_{2}$ among the severe SCD patients indicates that this haplotype may have pharmacogenetic implications, perhaps therapeutic implication of genetic variations in the eNOS gene. This study is the first report of an association between all three SNPs of eNOS gene polymorphism and SCD patients in the 
world. However, in view of lack of sufficient studies in different ethnic population of India and other countries on eNOS gene polymorphism in SCD patients, further studies with increased number of individuals carrying these polymorphisms may be planned to extend the results of this study.

\section{CONCLUSION}

In conclusion, our results suggest that $e N O S$ gene polymorphism is associated with SCD and it may act as genetic modifier of phenotypic variation of these patients. However, further investigation with large sample size is needed to confirm these associations.

\section{CONFLICT OF INTEREST}

The authors declare no conflicts of interest.

\section{ACKNOWLEDGEMENTS}

This work was supported by financial assistance from DBT-Indian Institute of Science Research Associateship Programme, Indian Institute of Science, Bangalore, given to Dr Sudhansu Sekhar Nishank and it is also supported partially by Regional Medical Research Centre for Tribals (ICMR), Jabalpur. We are grateful to the Director, RMRCT (ICMR) for her kind help and valuable suggestion in preparing this manuscript. Thanks goes to all staff of the Department of Genetics, RMRCT (ICMR) for their lab-related helps in various ways.

1 Weatherall, D. J. The inherited diseases of hemoglobin are an emerging global health burden. Blood 115, 4331-4336 (2010).

2 Wood, K. C., Hsu, L. L. \& Gladwin, M. T. Sickle cell disease vasculopathy: a state of nitric oxide resistance. Free Radical Biol. Med. 44, 1506-1528 (2008).

3 Mack, A. K. \& Kato, G. J. Sickle cell disease and nitric oxide: A paradigm shift? Int. J. Biochem. Cell Biol. 38, 1237-1243 (2006).

4 Pritchard, K. A. Jr., Ou, J., Ou, Z., Shi, Y., Franciosi, J. P., Signorino, P. et al. Hypoxia induced acute lung injury in murine models of sickle cell disease. Am. J. Physiol. Lung Cell Mol. Physiol. 286, L705-L714 (2004).

5 Tsukada, T., Yokoyama, K., Aria, T., Takemoto, F., Hara, S., Yamada, A. et al. Evidence of association of the eNOS gene polymorphism with plasma NO metabolite levels in humans. Biochem. Biophysics. Res. Commun. 245, 190-193 (1998).

6 Kunnas, T. A., Ilveskoski, E., Niskakangas, T., Laippala, P., Kajander, O. A., Mikkelsson, J. et al. Association of the endothelial nitric oxide synthase gene polymorphism with risk of corobnary artery disease and myocardial infarction in middle-aged men. J. Mol. Med. 80, 605-609 (2002).

7 Voetsch, B., Jin, R. C. \& Loscalzo, J. Nitric oxide insufficiency and atherothrombosis. Histochemical Cell Biol. 122, 353-367 (2004).

8 Sinici, I., Guven, E. O., Serefoglu, E. \& Hayran, M. T-786C polymorphism in promote of eNOS gene as genetic risk factor in patients with erectile dysfunction in Turkish population. J. Urol. 75, 955-960 (2009).

9 Endres, M., Laufs, U., Liao, J. K. \& Moskowitz, M. A. Targetting eNOS for stroke protection. Trends Neurosci. 27, 283-289 (2004).

10 Wang X. Li \& Wang, J. Endothelial nitric oxide synthase gene sequence variations and vascular disease. Mol. Genet. Metab. 70, 241-251 (2000).

11 Chaar, V., Tarer, V., Etienne-Julan, M., Diara, J. P., Elion, J. \& Romana, M. ET-1 and eNOS gene polymorphisms and susceptibility to acute chest syndrome and painful vaso-occlusive crises in children with sickle cell disease. Hematologica 91, 1277-1278 (2006).

12 Sharan, K., Surrey, S., Ballas, S., Borowski, M., Devoto, M., Wang, K. F. et al. Association of T- 786C eNOS gene polymorphism with increased susceptibility to acute chest syndrome in females with sickle cell disease. Br. J. Hematol. 124, 240-243 (2004).
13 Mohanty, D. \& Mukherjee, M. B. Sickle cell disease in India. Curr. Opin. Hematol. 9, 117-122 (2002).

14 Ahluwalia, T. S., Ahuja, M., Rai, T. S., Kohli, H. S., Sud, K., Bhansali, A. et al. Endothelial nitric oxide synthase gene haplotypes and diabetic nephropathy among Asian Indians. Mol. Cell Biochem. 314, 9-17 (2008).

15 Gururajan, P., Gurumurthy, P., Victor, D., Rao, G. S. N., Babu, R. S., Bharati, A. S. et al. Plasma total nitric oxide and endothelial constitutive nitric oxide synthase (ecNOS) gene polymorphism: a study in south Indian population. Biochem. Genet. 49, 96-103 (2010).

16 El-Hazmi, M. A. Clinical and hematological diversity of sickle cell disease in Saudi children. J.Trop. Pediatr. 38, 106-112 (1992).

17 Akhtar, M. S., Biswas, A., Ranjan, R., Sharma, A., Kumar, S. \& Saxena, R. The nitric oxide synthase 3 gene polymorphisms and their association with deep vein thrombosis in Asian Indian patients. Clin. Chim. Acta 411, 649-652 (2010).

18 Tang, Z., Junyao, Li, Jianhong, M. M. \& Jianhong Yang, M. M. Relationship of endothelial nitric oxide synthase gene polymorphism with blood pressure, lipid profile and blood glucose level. Front. Med. 2, 178-181 (2008).

19 Vargas, A. E., deSilva, M. A. L., Silla, L. \& Chies, J. A. B. Polymorphisms of chemokine receptors and eNOS in Brazilian patients with sickle cell disease. Tissue Antigens 66, 683-690 (2005).

20 Lopez, B. L., Barnett, J., Ballas, S. K., Christopher, T. A., Davis-Moon, L. \& Ma, X. Nitric oxide metabolite in acute vaso-occlusive sickle cell crisis. Acad Emerg Med 3, 1098-1103 (1996).

21 Yoon, Y., Song, J. \& Hong, S. H. Plasma nitric oxide concentrations and nitric oxide synthase gene polymorphisms in coronary diseases. Clin. Chem. 46, 1626-1630 (2000).

22 Afrasyap, L. \& Ozturk, G. NO level and endothelial NO synthase gene polymorphism(Glu298Asp) in the patients with acute coronary disease from the Turkish population. Acta Biochem. Biophy. Sin. 36, 661-662 (2004).

23 Fatini, C., Sofi, F., Gensini, F., Sticchi, E., Lari, B., Pratesi, G. et al. Influence of eNOS gene polymorphisms on carotid Atherosclerosis. Eur. J. Vasc. Endovasc. Surg. 27, 540-544 (2004).

24 De Marco, K. C., Antunes, L. M. G., Tanus-Santos, J. E. \& Barbosa, F. Jr. Intron 4 polymorphism of the endothelial nitric oxide synthase (eNOS) gene associated with decreased NO production in mercury exposed population. Sci. Total Environ. 414, 708-712 (2011).

25 Glueck, C. J., McMahon, R. E., Bouquot, J. E., Khan, N. A. \& Wang, P. T-786C polymorphism of endothelial nitric oxide synthase gene and neuralgia-inducing cavitational osteonecrosis of the jaws. Oral. Surg. Oral. Med. Oral. Pathol. Oral. Radiol. Endod. 109, 548-553 (2009).

26 Hingorani, A. D. Endothelial nitric oxide synthase polymorphisms and hypertension. Curr. Hypertens. Rep. 5, 19-25 (2003).

27 Shankarishan, P., Borah, P. K., Ahmed, G. \& Mahanta, J. Prevalence of endothelial nitric oxide synthase(eNOS) gene exon7 Glu298Asp variant in North eastern India. Indian J. Med. Res. 133, 487-491 (2011).

28 Angeline, T., Isabel, W. \& Tsongalis, G. J. Experimental and molecular pathology. Endothelial nitric oxide gene polymorphisms, nitric oxide production and coronary artery disease risk in a South Indian population. Exp. Mol. Pathol. 89, 205-208 (2010).

29 Nagasaki, S., Metzger, I. F. \& Suza-Costa, D. C. eNOS genotype is withouteffect on circulatingnitrite/nitrate level in healthy male population. Thromb. Res. 115, 375-379 (2005).

30 Nejatizadeh, A., Kumar, R., Stobdan, T., Goyal, A. K., Sikdar, S., Gupta, M. et al. Endothelial nitric oxide synthase gene haplotypes and circulating nitric oxide levels significantly associate with risk of essential hypertension. Free Radic. Biol. Med. 44, 1912-1918 (2008).

31 Sandrim, V. C., De Syllos, W. C., Lisboa, H. R. K., Tres, G. S. \& Tanus-Santos, J. E. Influence of eNOS haplotypes on the plasma nitric oxide products concentrations in hypersensitive and type 2 diabetes mellitus patients. Nitric Oxide 16, 348-355 (2007).

32 Metzger, I. F., Sertorio, J. T. C. \& Tanus-Santos, J. E. Modulation of nitric oxide formation by endothelial nitric oxide synthase gene haplotypes. Free Radic. Biol. Med. 43, 987-992 (2007).

33 Shin, S. J., Lee, H. H., Cha, S. H., Kim, J. H., Shim, S. H., Choi, D. H. et al. Endothelial nitric oxide synthase gene polymorphisms ( $-786 \mathrm{~T}>\mathrm{C}, 4 \mathrm{a} 4 \mathrm{~b}, 894 \mathrm{G}>\mathrm{T}$ ) and haplotypes in Korean patients with recurrent spontaneous abortion. Eur. J. Obst. Gyne. Reprod. Biol. 152, 64-67 (2010).

34 Serjeant, G. R. The emerging understanding of sickle cell diseaseee. Br. J. Haematol. 112, 3-18 (2001).

Supplementary Information accompanies the paper on Journal of Human Genetics website (http://www.nature.com/jhg) 